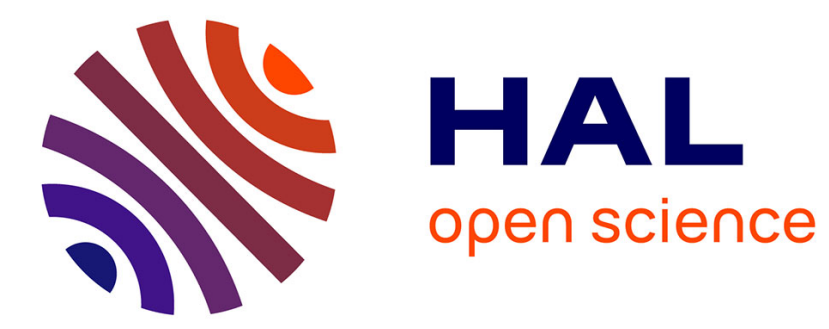

\title{
COMPUTER SIMULATION STUDIES OF MIGRATION MECHANISMS IN IONIC GLASSES AND LIQUIDS
}

C. Angell, P. Cheeseman, S. Tamaddon

\section{- To cite this version:}

C. Angell, P. Cheeseman, S. Tamaddon. COMPUTER SIMUlATION STUDIES OF MIGRATION MECHANISMS IN IONIC GLASSES AND LIQUIDS. Journal de Physique Colloques, 1982, 43 (C9), pp.C9-381-C9-385. 10.1051/jphyscol:1982972 . jpa-00222501

HAL Id: jpa-00222501

https://hal.science/jpa-00222501

Submitted on 1 Jan 1982

HAL is a multi-disciplinary open access archive for the deposit and dissemination of scientific research documents, whether they are published or not. The documents may come from teaching and research institutions in France or abroad, or from public or private research centers.
L'archive ouverte pluridisciplinaire HAL, est destinée au dépôt et à la diffusion de documents scientifiques de niveau recherche, publiés ou non, émanant des établissements d'enseignement et de recherche français ou étrangers, des laboratoires publics ou privés. 


\title{
COMPUTER SIMULATION STUDIES OF MIGRATION MECHANISMS IN IONIC GLASSES AND LIQUIDS
}

\author{
C.A. Angell, P.A. Cheeseman and S. Tamaddon \\ Department of Chemistry, Purdue University, West Lafayette, Indiana 47907, \\ U.S.A.
}

\begin{abstract}
Résumé. - Les mécanismes de migration des cations et des anions dans les verres et liquides du type silicate et fluorure simulés ont été étudiês par des méthodes de dynamique moléculaire à l'ordinateur. On donne des exemples montrant la puissance de la méthode. On montre I'existence d'un minimum de viscosité aux pressions élevées pour des aluminosilicates fondus.

Abstract. - Ion dynamics computer simulations of the migration of cation and anions in "computer glasses" and liquids of silicate and fluoride types are reported, and examples of the diagnostic power of the simulation method are given. The existence of high pressure minima in the viscosity of molten aluminosilicates is indicated.
\end{abstract}

Introduction. - In this paper we will review briefly the way in which the use of ion dynamics computer simulation studies can help develop concepts for, and models of, ionic motion in both rigid glasses and high-temperature ionic liquids. The description will cover (1) cases in which the physical properties of the normal substance are directly simulated, and (2) cases in which the special ability of the simulation programs to introduce changes in the system (for instance, a change of mass without change of interionic potential) which cannot be introduced in laboratory experiments, is used to reveal features of the migration mechanism which otherwise might be difficult to recognize.

Considering migration in solid glasses first, we reproduce in Fig. I the a.c. conductivity (or absorptivity) over a wide frequency range for a well-studied system, $\mathrm{Na}_{2} \mathrm{O} \cdot 3 \mathrm{SiO}_{2}$ glass, in order to draw attention to those features of the observed behavior which the simulation should help to explain. Fig. 1 shows the electrical conductivity over a wide frequency range from $10^{-1}-10^{14} \mathrm{~Hz}$ based on data from a number of different studies to which reference can be found in Ref. 1. We see, firstly, a frequency-independent but strongly temperature-dependent part of the conductivity response which is related directly to the diffusivity of the alkali cation in this material. Secondly, we see a frequency-dependent region with a maximum at $\sim 10^{13} \mathrm{~Hz}$ in which the conductivity is comparatively independent of temperature. This is observed experimentaliy using far infra-red spectroscopy. Thirdly, we see a more or less temperature independent, constant slope, regime which connects the high frequency and low frequency extremes. This frequency-dependent regime conforms to the simple relation

$$
\sigma(\mathrm{f})=\mathrm{kf}^{\alpha}
$$

where $\alpha \simeq 1.0$

The simulation, then, should show features which correspond with each of these regions and hopefully will provide a mechanistic interpretation of their existence.

Simulations of the cases of alkali migration in silicate glasses, and also for fluoride anion conduction in fluorozixconate glasses, were performed using a multicomponent ion dynamics program described in previous publications (2). The potential of interaction for the various possible pairs of ions in the simulated stretches is assumed to be a simple two term function (coulomb + exponential repulsion)

$$
u_{i j}(r)=e^{2} z_{i} z_{j} / r_{i j}+b_{i j} \exp \left[\left(\sigma_{j}+\sigma_{j}-r_{i j}\right) / \rho\right]
$$


The parameters used in Eq. (2) in this study are collected in Table 1 below. The number of ions in the primary computational box was of order 200, and details of the calculation and of limitations on its accuracy are given in earlier publications $(2,7)$

Table 1

Alkali Silicate and Alumino Silicate

\begin{tabular}{|c|c|c|c|c|c|}
\hline Species & $\sigma$ & & $\mathbf{j}^{(1}$ & ex & \\
\hline & & $\mathrm{Si}$ & 0 & $\mathrm{Na}$ & A1 \\
\hline Si & 1.33 & 3.42 & & & \\
\hline & 1.42 & 2.117 & 0.814 & & \\
\hline $\mathrm{Na}$ & 1.252 & 2.898 & 1.595 & 2.375 & \\
\hline Al & 1.358 & 3.372 & 2.070 & 2.850 & 3.325 \\
\hline
\end{tabular}

\begin{tabular}{|c|c|c|c|c|c|}
\hline \multirow{5}{*}{$\rho=0.29$} & \multicolumn{4}{|c|}{ Barium Fluorozirconate } & \\
\hline & & & $2 r$ & $\mathrm{Ba}$ & F \\
\hline & $2 x$ & 1.28 & 3.80 & & \\
\hline & $\mathrm{Ba}$ & 1.49 & 3.325 & 2.85 & \\
\hline & $F$ & 1.33 & 2.613 & 2.138 & 1.425 \\
\hline
\end{tabular}

Fig. 1 : Experimental frequency spectr.

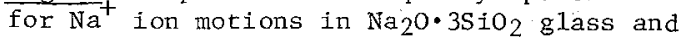
liquid state at different temperatures. For alkali silicate glasses,

$$
\sigma(f) \approx 1.01 \times 10^{-2} \alpha(f)
$$

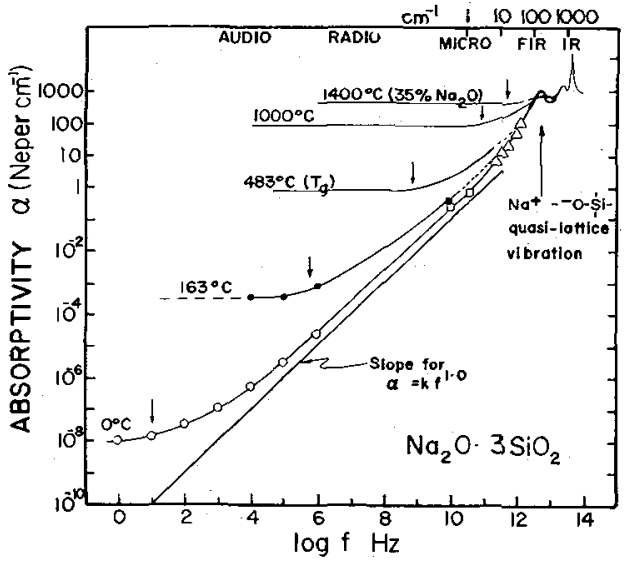

Alkali Cation Migration. - We report basic findings for the dynamics sodium silicate "glass" very briefly (they have been published previously) (2), in order to describe here previously unpublished "experiments" from which new insight into the migration mechanism can be obtained. The character of the alkali motions observed in $\mathrm{Na}_{2} \mathrm{O} \cdot 3 \mathrm{SiO}_{2}$ glass is demonstrated by $\mathrm{Fig}$. 2a in which the trajectories for all the sodium ions in the primary computational box are projected onto one of its faces. The diagram shows two stages in the evolution of the motions, the first after $0: 1 \mathrm{ps}$ has elapsed since the beginning of the run and the second after ten times as long in which the development of trajectory "channels" can be seen. Evidently the ions are spending some time oscillating anharmonically ("rattling") in a preferred location in the structure, and some time drifting in certain preferred directions between such sites. The effective oscillation frequency is obtained by a print-out of the number of reversals of the trajectory, and corresponds to a frequency of $200 \mathrm{~cm}^{-1}$ in good agreement, with the observed strong far infra-red band centered at $220 \mathrm{~cm}^{-1}$ (4). The drifting motion can be described by the familiar mean-squared displacement (average value) as a function of time, which is depicted in Fig. 2b. From the long-time slope of this curve a diffusion coefficient at the temperature of the calculation, of $1.3 \times 10^{-5} \mathrm{~cm}^{2} \mathrm{sec-1}$ is obtained. Using the Nernst-Einstein equation with correlation factor $f=0.4$, this value of $D_{\mathrm{Na}}$ predicts an electrical conductivity of $1.2 \Omega^{-1} \mathrm{~cm}^{-1}$ which agrees with experiment within $25 \%\left(\sigma 1500 \mathrm{~K}=0.95 \Omega-\Omega_{\mathrm{cm}}{ }^{-1}\right)$.

To understand what determines the range over which the drifting motion can occur, hence the relation between long range and limited range (non-diffusive motions) we conduct experiments in which the mass of the oxide ion is artificially changed to a large number to observe how the sodium ion mobility is affected. In the ideal fast ion conductor the motion of the conducting species is completely decoupled from that of the lattice, and change of anion mass would have no effect. The strong decrease in $\mathrm{Na}^{+}$displacement which in fact follows from an increase in oxide ion mass has been described earlier (2), and in the present paper we conduct further "experiments" to elucidate the origin of this effect. 


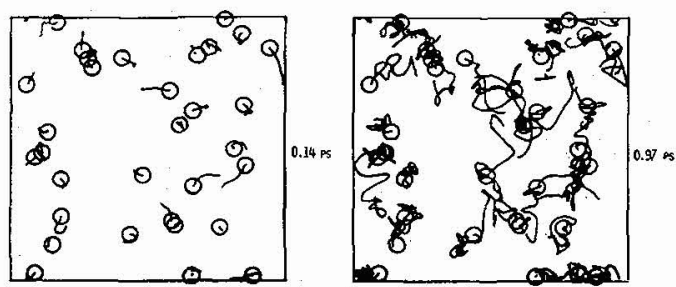

Fig. 2 (a) : $\mathrm{Na}^{+}$trajectories, over short (0.14 ps) and long ( $0.97 \mathrm{ps)}$ time periods projected onto a box side.

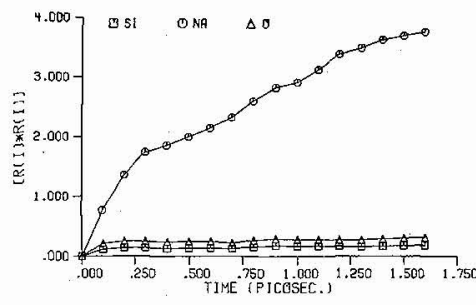

(b) : Mean-squared displacement of all. ions in $\mathrm{Na}_{2} \mathrm{O} .3 \mathrm{SiO}_{2}$ at $1500 \mathrm{~K}$.

In the present work the mass of oxide ions in the system has been selectively increased from 16 to 160 amu depending on whether the oxide performs a bridging or a nonbridging function in the glass. This can be simply determined from examining a print-out of the near neighbors of all oxides in the system and assigning bridging functions to all those which have two silicon ions within a distance of $2.0 \AA$. The simulation is then continued, starting from the same initial configuration after entering the new species and species mass assignments in the input data.

The results of these experiments are shown in Fig. 3, where the mean-squared displacement of the sodium ions over a period of 2.0 ps for the two cases of heavy bridging and heavy nonbridging oxygens is compared with the result found for the normal oxide mass case. We see that the sodium ion motion is slightly accelerated when the nonbridging oxygens are made heavy, but is greatly depressed when the bridging oxygens are made heavy.

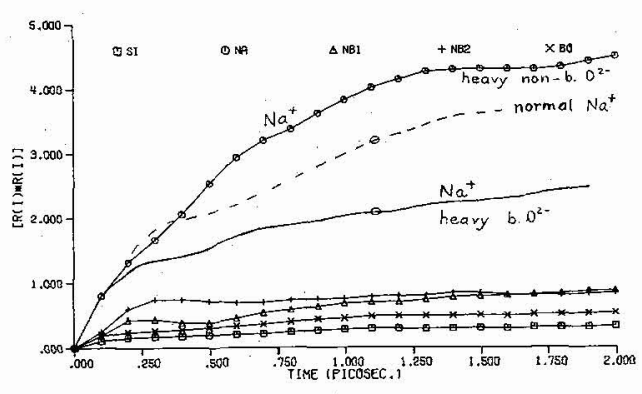

Fig. 3 (a) : Mean-squared displacement of $\mathrm{Na}^{+}$ions for normal $\mathrm{Na}_{2} \mathrm{O} \cdot 3 \mathrm{SiO}_{2}$ at $1500 \mathrm{~K}$, and for cases of (i) heavy bridging oxide ions and (ii) heavy nonbridging oxide ions, showing braking effect of the latter.

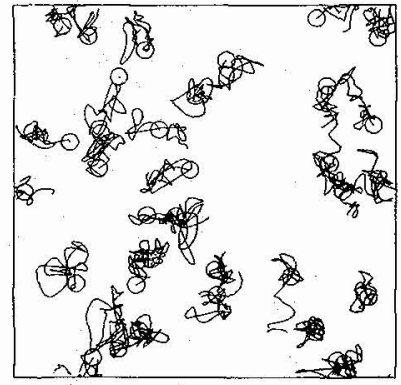

(b) : Trajectories of $\mathrm{Na}^{+}$ions in presence of heavy nonbridging ionic showing localization of $\mathrm{Na}^{+}$ions (rattle and limited drift motion).

The sodium ion trajectories obtained in the latter case are shown in Fig. 3b. It is seen that the distance that the sodium ions travel in this case is limited, so that the conducting "channels" have effectively disappeared. This implies that nonbridging oxygens in the structure serve to provide the barriers which limit the motion of the alkali ions: increasing the mass of these ions has effectively closed the channels for the conditions of this calculation. The exact manner in which the heavy mass serves to close the channels is not made clear by these experiments. It may be either a vibrational amplitude effect, in which the increase in mass, by restricting the amplitude of displacement, reduces the possibility of a sodium ion slipping through the bottleneck, or it may simply be a result of the increased mass more effectively back-scattering the approaching alkali cations, an inertial effect distinct from the first-mentioned. The experiment, however, serves to focus attention on the nonbridging oxygens as the limiting factor in the migration of the alkali ions, an observation which is, of course, in good accord with the exponential increase in conductivity as the number of nonbridging oxygens in the structure is reduced with increasing alkali ion content (though the reason for the slope of 0.5 found for $\log \sigma$ vs $\%$ alkali is not as obvious as in the weak electrolyte model(5)). 
The motions seen in Fig. 3b also have rattle, $190 \mathrm{~cm}^{-1}$, and drift components, but the drift is now limited and will result in a frequency dependent loss dependent on the channel lengths. This will contribute in the $\sigma(f)=k f^{\alpha}$ regime, which is thus identified as a necessary accompaniment of the gated channel conductance mechanism.

Fluoride Anion Motion. - Turning to fluoride ion motion, differences from the case described above must be expected because in this case there is only one anion in the system, i.e., an obvious mobile species like the alkali cation, has not been introduced into the system. Simulations carried out on a prototype binary fluorozirconate "glass" with molar proportions $64 \mathrm{ZrF}_{4}: 36 \mathrm{BaF}_{2}$ but not described in detail here have indicated a structural organization in which each zirconium is surrounded by $7 \mathrm{fluo-}$ ride ions, 4 of which perform a bridging function-to second nearest neighbor zirconium ions. The remaining 3 have bariums as their second nearest neighbors, the symmetry of the arrangement being variable throughout the structure.

In order to determine whether all fluoride ions in the structure are equally mobile, or whether the nonbridging fluorides are the most mobile, we have, as before, identified the fluoride ions in the structure according to whether they have one or two nearest neighbor zirconium ions. The two classes are then distinguished from one another in the program, and a simulation run is initiated. Given sufficient time the existence of exchanges of fluorides between different zirconium centers during the progress of diffusion should eliminate the distinction between the bridging and nonbridging fluorides, so the duration of the run has been limited. Also the temperature of the run was chosen so that slower of the two species undergo few or no exchanges between $\mathrm{Zr}^{4+}$ centers during the run.

The results are shown in Fig. 4. This experiment, which we regard as very qualitative and preliminary, suggests that the bridging fluoride ions are indeed more mobile than the nonbridging, although the latter still drift further in the course of the short run than do the zirconium or the barium species which effectively provide a "frozen" matrix within which the fluoride ions can migrate. It remains for further work to show how this ability is influenced by changes of composition which produce more nonbridging fluorides.

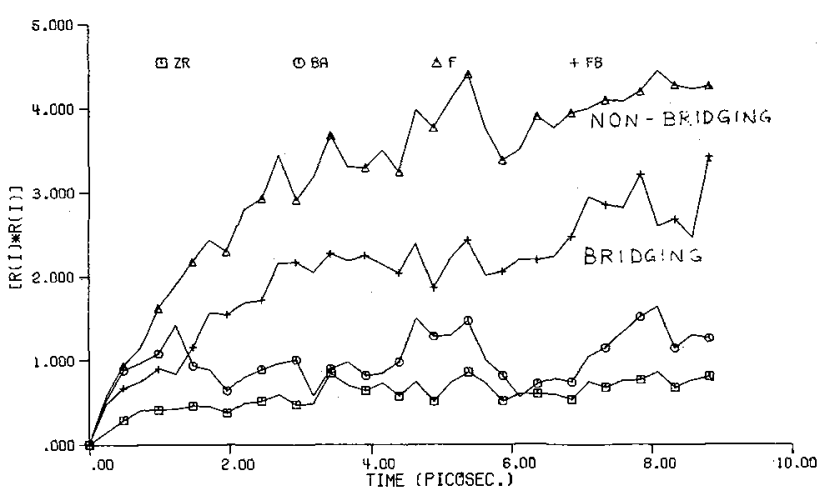

Fig. 4 : "Single pass" mean-square displacement vs. time plots at $1200 \mathrm{~K}$ for ions in the system $\mathrm{ZrF}_{4}+\mathrm{BaF}_{2}$ in which the $\mathrm{F}^{-}$component has been separated into bridging $(\mathrm{Zr}-\mathrm{F}-\mathrm{Zr})$ and nonbridging $(\mathrm{Zr}-\mathrm{F}-(\mathrm{Ba}))$ types, defined at $t-0^{\prime}$. Since the system so defined is not an equilibrium system only a single pass starting at $t=0$ has been made, which accounts for greater noise level.

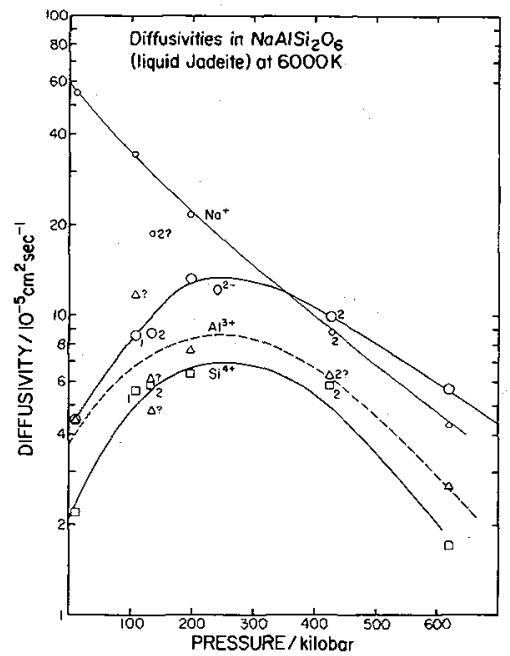

Fig. 5 : Isothermal pressure dependence of the ionic diffusivities in a liquid aluminosilicate of low pressure open network type. Note the water-like diffusivity maximum for the network ions at 200-300 kbar implying a viscosity minimum in the same pressure range. 
Motion of Network Ions in Molten Silicates. - Turning now to the study of certain problems of interest in fully fluid ionic glass-forming systems, we examine the behavior of some very high temperature silicate systems. These are of interest not only as glass-forming materials, but as geochemical systems of the type which are responsible for most of the earth's continental crust, (aluminosilicates with various charge-compensating cations such as $\mathrm{Na}^{+}, \mathrm{K}^{+}, \mathrm{Ca}^{++}$).

The question of interest which we wish to examine in this case is whether or. not the choice of compositions which favor, at low temperatures, expanded network structures, will behave like water in their response to increases in pressure, i.e., whether increase in pressure will cause the fluidity of the material to increase anomalously, rather than decrease, as is the case with most liquids. Laboratory. studies on liquid jadeite, NaAlSi${ }_{2} \mathrm{O}_{6}$ which observed that pressure increases to 40 kbar caused a rapid lowering of the viscosity at $1350^{\circ} \mathrm{C}$, were reported by Kushiro in 1976, and similar results have been found for several other silicate melts since that time. Such behavior would be reflected in our simulation studies by increases with pressure in the ionic diffusivities for the ionic species $\mathrm{Si}^{4+}, \mathrm{Al}^{3+}$, and $\mathrm{O}^{2-}$ which make up the quasilattice of the liquid. However, with the unlimited pressure range of the ion dynamics method, the pressure at which the mobilities, hence the fluidity, would pass through maximum values (as in the case of water) could be identified.

In Fig. 5 we show results for NaAlSi. $\mathrm{O}_{6}$ at $6000 \mathrm{~K}$, an high temperature being chosen in order that the ions displace sufficiently in economically reasonable computing times for the calculated diffusion coefficients to be reasonably reliable. The results indeed show the existence of mobility maximum in the vicinity of 2-300 kbar. Examination of the average coordination number of the Si4t ions with structure suggest that the mobility maximum correlates with a maximum prevalence of the unstable coordination state 5 , consistent with the observations by Brawer on BeF2 glass (6).

Another feature of interest in Fig. 5 is the contrast in pressure dependences of the network ions and the interstitional $\mathrm{Na}^{t}$ ions. The rapid decrease in $\mathrm{D}_{\mathrm{Na}}+$ at all pressures is clearly a consequence of the collapse of the open channel structure with decreasing volume. For such ions the Stokes-Einstein equation would evidently fail even to predict the sign of the pressure dependence.

Elsewhere, we have shown how these anomalous characteristics may be removed by addition of excess oxide ion to chemically break down the framework structure, a result which is also consistent with laboratory experiments at lower temperature.

ACKNOWLEDGEMENT. - This work was supported in part by the National Seience Foundation U.S.A. under NSF-MRL Grant 80-20249 and Solid State Chemistry Grant DMR 8007053. Fluoride glass studies were assisted by Hanscomb Air Force Base. REFERENCES

1. ANGELL C. A. and WONG J., Glass: Structure by Spectroscopy, ed. Marcel Dekker, New York (1976) chapter 11,750.

2. ANGELL C.A., BOEHM L., CHEESEMAN P. A., and TAMADDON S, Solid State Ionics 5 (1981) 597 .

3. SOUlES T. F., J. Chem. Phys. 71 (1979)4570: 75 (1981) 969 .

4. EXARHOS G. J., MILLER P. J., and RISEN W. M., J. Chem. Phys. 60 (1974) 4145.

5. RAVAINE D. and SOUQUET J. L., Phys. Chem. Glasses 18 (1977) 27. INGRAM M. D., MOYNIHAN C. J. and LESIKAR A. V., J. Non-Cryst. So1. 38,39 (1980) 371.

6. BRAWER S. A. , J. Chem. Phys. 75 (1981) 3510. 